\title{
GESTÃO DE DESIGN E O FUTURO DOS NEGÓCIOS: VER, PREVER E TORNAR VISÍVEL EM UM CONTEXTO DE MUDANÇAS
}

\author{
Márcia Bergmann \\ Puc-Rio \\ marciabergmann@gmail.com \\ Cláudio Magalhães \\ Puc-Rio \\ claudio-design@puc-rio.br
}

Resumo: Mudanças no contexto de atuação das empresas são inevitáveis, mas podem ser previstas. Por isso, o design é considerado uma força transformadora ao perceber mudanças e reconhecer oportunidades. A partir desse pressuposto, buscou-se compreender como o design contribui para as organizações desenvolverem vantagens competitivas no longo prazo. Para tal, a revisão bibliográfica se concentrou principalmente na teoria da gestão de design e do design estratégico. Ao enfrentar situações desconhecidas, novas formas de pensar são necessárias, assim, foram apresentadas especificidades do design no processo de desenvolver ideias para o futuro. $O$ trabalho enfatiza o caráter inventivo, plural e propenso ao risco do design como fator essencial aos processos estratégicos no quais a incerteza é um elemento intrínseco.

Palavras-chave: gestão de design, design estratégico, futuro, cenários.

Abstract: Changes in the business context is inevitable, but can be predicted. Therefore, the design is considered a transforming force to notice changes and recognizing opportunities. From this assumption, we sought to understand how design helps organizations develop competitive advantages in the long run. To this end, the literature review focused mainly on the theory of design management and strategic design. When facing unknown situations, new ways of thinking are needed, so the design specifics were presented in the process of developing ideas for the future. The work emphasizes the inventive, plural and prone to the risk character of design as a key factor to strategic processes in which uncertainty is an intrinsic element.

Keywords: design management, strategic design, future, scenarios. 


\section{INTRODUÇÃO}

Existe um crescente entendimento por parte das organizações de que o design estratégico é um recurso valioso para alcançar objetivos corporativos. Cabe a ele colaborar para uma melhor compreensão de situações complexas, ajudando as empresas a estruturarem o ambiente em que se encontram e a torná-lo compreensível na busca por sustentabilidade no longo prazo. Por isso, o objetivo deste artigo foi compreender de que modo o design contribui para as empresas se prepararem para enfrentar mudanças e conquistarem vantagens competitivas no futuro. A pesquisa foi realizada principalmente a partir da revisão bibliográfica no campo do design, mas também considerou conceitos da administração de empresas, no que se refere a estratégias corporativas. Elaborado em três partes, o artigo destaca, em primeiro lugar, as funções da gestão do design, seu modus operandi e sua evolução até a consolidação do design estratégico; depois, discorre sobre a gestão de design no século XXI, abordando a pluralidade de perspectivas a partir de mudanças no contexto em que o design atua; por fim, apresenta as relações entre design estratégico, o entorno das organizações e habilidades do design para contribuir para o processo de fazer previsões.

\section{GESTÃO DE DESIGN E A SUA TRAJETÓRIA ATÉ O DESIGN ESTRATÉGICO}

A gestão de design, ao longo das últimas décadas, consolidou-se na esfera empresarial como um fator-chave para o sucesso. As empresas estão mais conscientes do papel e do valor do design, pois este é um importante recurso para todos os tipos de negócios (Holston, 2011). Apesar de, originalmente, ser uma atividade econômica intrínseca à indústria e à fabricação de bens tangíveis - de maior ou menor complexidade - o design tem atuado progressivamente em projetos de serviços e experiências (Viladas, 2010). No âmbito corporativo, o design tem mostrado ser relevante ao abordar problemas complexos de forma holística, com o objetivo de elaborar a melhor solução possível para todas as partes envolvidas nas esferas econômica, social e ambiental. Por exemplo, ele é capaz de influenciar a compra, satisfazer o consumidor, melhorar processos, reduzir custos, aumentar a visibilidade da marca, identificar novos mercados, formular novas estratégias (Best, 2010). Contudo, o design expandiu seus domínios, atuando também em órgãos de serviço público e em instituições privadas sem fins lucrativos (Cooper, 2009). Tantas áreas de atuação são oportunidades para o design crescer em importância e valor no século XXI, redefinindo as suas fronteiras (Cooper e Junginger, 2011).

A gestão de design como termo, conceito e descrição de uma atividade prática e de pesquisa surgiu em 1964, no Reino Unido, e um dos seus principais objetivos foi trazer ao design a consciência da gestão, significando incorporar processos administrativos (Cooper e Junginger, 2011). Como qualquer outra atividade corporativa, o design pode e precisa ser administrado (Von Stamm, 2004), assim, cabe à gestão de design planejar, executar, coordenar e controlar as ações inerentes ao processo de design nas empresas (Cooper e Press, 1995). De outra forma, as vantagens do design podem ser perdidas e os resultados desejados podem não ser obtidos. Por isso, a gestão de design incorpora visões, metas e objetivos; exige recursos de coordenação e comprometimento; envolve processos e pessoas na área especificamente relacionada ao design; integra os designers a outras áreas 
organizacionais (Best, 2010). Ela é responsável não somente por desenvolver corretamente o produto, enquanto uma atividade em busca de eficiência, mas, principalmente, por desenvolver o produto certo, enquanto uma atividade que ambiciona conquistar eficácia (Magalhães, 1997). Através de uma ação mais ampla e global, a gestão conecta o design aos objetivos corporativos - operacionais e estratégicos - posicionando-o em um patamar maior de responsabilidades na corporação (Best, 2015).

O papel do design nos negócios mudou significativamente ao longo do tempo (Lockwood, 2010) e a gestão de design evoluiu desde os anos 1960 até o começo do século XXI, registrando mudanças expressivas (Cooper e Junginger, 2011). De forma sintética, as diferentes abordagens do design se resumem: à ênfase no design como valor econômico nos anos 1980; à integração do design à cadeia de valor entre $1990 \mathrm{e}$ 1995; ao valor estratégico do design entre 1995 e 2000; ao design como ativo intangível $^{1}$ na gestão das empresas entre 2000 e 2010 (Mozota, 2011). A primeira metade deste último período testemunhou uma fase de crescimento global e evidenciou uma valorização da gestão de design, pois "criatividade" e "inovação" se tornaram palavras de ordem na economia mundial e, como resultado, o design conquistou mais responsabilidades e passou a lidar com questões mais complexas (McCullagh, 2010). No entanto, o contexto em que as empresas operavam começou a mudar em meados da década de 2000 e a gestão de design foi impactada por preocupações econômicas, ecológicas e éticas (Cooper e Junginger, 2011). Ela passou a lidar com aspectos críticos, que demandaram uma reflexão sobre seus propósitos, buscando colocar o pensamento de design a serviço da cidadania (Press e Cooper, 2003).

As principais funções da gestão do design são administradas simultaneamente em três diferentes níveis: a gestão operacional de design, empregada no processo de desenvolvimento de produtos; a gestão funcional de design associada ao gerenciamento de projetos; a gestão estratégica de design, aplicada na estrutura organizacional (Bruce e Cooper, 1997; Press e Cooper, 2003; Martins e Merino, 2011; Mozota et al., 2011). Em termos operacionais, o design é uma ferramenta para explorar oportunidades de mercado no que se refere ao desenvolvimento de produtos e serviços (Best, 2010). Os propósitos e as ênfases da gestão de design no nível gerencial envolvem a habilidade de coordenação de processos, funções e recursos (Mozota et al., 2011); administra não somente a inovação, mas também os riscos inerentes (Best, 2015). No nível do planejamento corporativo, o design estabelece a relação entre a situação concreta, enquanto realidade percebida, e a situação projetada, enquanto realidade desejada (Mozota et al., 2011). De forma conjunta, a gestão de design identifica e aloca ativos criativos em uma organização para criar vantagem estratégica sustentável (McBride, 2015).

O nível - operacional, funcional e estratégico - em que o design é administrado nas empresas é um dos parâmetros para classificá-las em diferentes estágios quanto à adoção da gestão de design. As tipologias de Dumas e Mintzberg (1991), de Tether (2005) e de Kootstra (2009), apesar de suas especificidades, apresentam convergência do uso do design basicamente nos seguintes estágios: sem gestão de design; gestão de design como projeto; gestão de design como função ou como processo; gestão de

\footnotetext{
${ }^{1}$ Ativo intangível referindo-se à habilidade valiosa, rara, inimitável e não substituível (Barney, 2002).
} 
design como cultura ou como estratégia. Os modelos hierarquizados de diagnóstico da gestão de design também auxiliam as empresas a identificar os fatores que a influenciam, tais como: consciência dos benefícios do design, incorporação do design aos processos organizacionais, integração do design ao planejamento firmas, competência em design e investimento em recursos para o design (Kootstra, 2009). Um resumo das características dos níveis de gestão de design e os fatores influenciadores é apresentado no Quadro 1.

Quadro 1 - Níveis de gestão de design e fatores influenciadores.

\begin{tabular}{|c|c|c|c|}
\hline \multirow{2}{*}{$\begin{array}{l}\text { FATORES } \\
\text { INFLUENCIADORES }\end{array}$} & \multicolumn{3}{|c|}{ NÍVEIS DE GESTÃO DE DESIGN } \\
\hline & OPERACIONAL & GERENCIAL & ESTRATÉGICO \\
\hline $\begin{array}{l}\text { Consciência dos } \\
\text { benefícios do } \\
\text { design }\end{array}$ & $\begin{array}{l}\text { Limitada aos } \\
\text { especialistas; relacionada } \\
\text { ao valor diferenciador do } \\
\text { design. }\end{array}$ & $\begin{array}{l}\text { Ampla, com abordagem } \\
\text { interdisciplinar; associada } \\
\text { ao valor coordenador do } \\
\text { design. }\end{array}$ & $\begin{array}{l}\text { Orientada pela alta } \\
\text { administração, impacta } \\
\text { todos os setores; relacio- } \\
\text { nada ao seu valor trans- } \\
\text { formador e inovador. }\end{array}$ \\
\hline $\begin{array}{l}\text { Incorporação do } \\
\text { design aos } \\
\text { processos } \\
\text { organizacionais }\end{array}$ & $\begin{array}{l}\text { Inconsistente e esporádica; } \\
\text { incluído tardiamente, } \\
\text { como consequência de } \\
\text { ações isoladas. }\end{array}$ & $\begin{array}{l}\text { Formal, orientado para o } \\
\text { desempenho; dissemina o } \\
\text { know how do design em } \\
\text { outros setores. }\end{array}$ & $\begin{array}{l}\text { Contínua, engajada na } \\
\text { estrutura organizacional e } \\
\text { ao pensamento } \\
\text { estratégico da empresa. }\end{array}$ \\
\hline $\begin{array}{l}\text { Integração do } \\
\text { design ao } \\
\text { planejamento } \\
\text { das organizações }\end{array}$ & $\begin{array}{l}\text { Ausente ou limitada ao } \\
\text { planejamento da oferta; } \\
\text { atende a uma proposta } \\
\text { inicial pré-definida. }\end{array}$ & $\begin{array}{l}\text { Existente e relevante ao } \\
\text { integrar, articular e gerir } \\
\text { equipes criativas. }\end{array}$ & $\begin{array}{l}\text { Integrante do } \\
\text { planejamento } \\
\text { estratégico; liderança nos } \\
\text { processos de inovação. }\end{array}$ \\
\hline $\begin{array}{l}\text { Competências de } \\
\text { design }\end{array}$ & $\begin{array}{l}\text { Específicas; ênfase na } \\
\text { solução de problemas de } \\
\text { produtos e serviços; } \\
\text { eficiência ao desenvolver } \\
\text { corretamente o projeto } \\
\text { com foco no usuário. }\end{array}$ & $\begin{array}{l}\text { Habilidades administrativas } \\
\text { de coordenação de } \\
\text { processos, funções e } \\
\text { recursos; orientação para a } \\
\text { inovação e gestão de risco. }\end{array}$ & $\begin{array}{l}\text { Avançadas; acréscimo da } \\
\text { dimensão estratégica, } \\
\text { com leitura do contexto, } \\
\text { desenvolvimento de } \\
\text { politicas, elaboração de } \\
\text { cenários futuros. }\end{array}$ \\
\hline $\begin{array}{l}\text { Investimento em } \\
\text { design }\end{array}$ & $\begin{array}{l}\text { Limitado a projetos } \\
\text { específicos. }\end{array}$ & $\begin{array}{l}\text { Suficiente, baseado no } \\
\text { potencial de retorno. }\end{array}$ & $\begin{array}{l}\text { Expressivo, com avaliação } \\
\text { de retorno e de risco. }\end{array}$ \\
\hline
\end{tabular}

Fonte: Elaborado pelos autores a partir de estudos de Dumas e Mintzberg (1991), Cooper e Press (1995), Magalhães (1995), Bruce e Cooper (1997), Press e Cooper (2003), Bruce e Bessant (2005), Tether (2005), DME (2009), Kootstra (2009), Martins e Merino (2011), Mozota et al. (2011), Best (2015), DMI (2015).

O foco e a responsabilidade do gestor de design variam de acordo com o contexto das organizações e a natureza de seus negócios (Bruce e Bessant, 2005). Mesmo duas firmas de tamanhos similares e que operam no mesmo setor, muitas vezes, adotam diferentes abordagens de gestão de design (Kootstra, 2009). Entretanto, observa-se que conforme as firmas avançam em cada estágio na direção do design estratégico, melhor é explorado o seu potencial (Viladas, 2010). Os modelos hierarquizados de identificação do estágio de gestão de design sugerem que, passando de um estágio ao outro gradativamente, a empresa se torna capaz de aperfeiçoar seus conhecimentos sobre design, alcançar as metas corporativas por meio dele e, ainda, indicam que a inclusão do design no nível mais estratégico cria condições para as empresas competirem de forma mais eficaz (Best, 2015). De todo o modo, a gestão de design é uma disciplina em contínuo movimento, se adaptando a um ambiente social e de negócios em constante transformação (Cooper, 2009). Ela enfrenta a crescente 
questão do que constitui um problema de design e, por isso, permanece expandindo seus territórios (Cooper e Junginger, 2011).

\section{GESTÃO DE DESIGN CONTEMPORÂNEA, CONTEXTO E PLURALIDADE}

O design - como uma prática social - pressupõe considerar e avaliar as situações nas quais ele acontece (Margolin, 2014). Afinal, as interações com o design ocorrem em um contexto, composto por uma confluência de circunstâncias sociais, culturais, tecnológicas e econômicas (Hekkert e Van Dijk, 2015). À medida que a complexidade do entorno da área de atuação do design se intensificou, os designers passaram a abordar questões mais complicadas e a lidar com um escopo mais amplo, turbulento e globalizado (Holston, 2011). As mudanças observadas no século XX e no início do século XXI influenciaram a abrangência, os métodos e os objetivos do design (Jussani e Krakauer, 2010). Por isso, não é possível abordar a gestão de design na atualidade sem considerar alguns aspectos do contexto contemporâneo mutável, no qual o design opera. O cenário - complexo e ilimitado (Zurlo, 2010) - é uma construção reflexiva dos designers, uma vez que não há visão do ambiente que não seja uma visão de quem o está observando (Mozota et al., 2011). Portanto, embora o Quadro 2 não seja exaustivo, ele apresenta aspectos relevantes da contemporaneidade.

Quadro 2 - Contexto contemporâneo de atuação do design.

\begin{tabular}{|l|l|}
\hline CONTEXTO & ASPECTOS EM DESTAQUE \\
\hline Social/cultural & $\begin{array}{l}\text { Envelhecimento da população; igualdade entre gêneros; pluralidade de identidades; } \\
\text { especificidades de pessoas com deficiências; crescimento da população urbana; } \\
\text { famílias uniparentais; preocupações com a violência social e terrorismo; estilos de vida } \\
\text { ecologicamente sustentáveis; migrações; ética e responsabilidade social. }\end{array}$ \\
\hline Tecnológico & $\begin{array}{l}\text { Redução de custos; democratização de acesso; miniaturização; personalização; } \\
\text { engenharia de materiais; velocidade, interatividade e conectividade; robótica e } \\
\text { prototipagem rápida; inserção de componentes eletrônicos; nanotecnologia, } \\
\text { biotecnologia e tecnologias digitais; convergência tecnológica. }\end{array}$ \\
\hline Econômico & $\begin{array}{l}\text { Globalização e acirramento da concorrência; fragmentação de mercados; novos } \\
\text { sistemas de produção e de consumo; empoderamento do consumidor; customização } \\
\text { em massa; integração entre trabalho e lazer; bem estar associado ao } \\
\text { compartilhamento; intensificação de transações comerciais eletrônicas. }\end{array}$ \\
\hline
\end{tabular}

Fonte: Elaborado pelos autores a partir da confluência de perspectivas de Bruce (2005), Bessant (2005), Hands (2009), Best (2010), Press (2011), Hekkert e Van Dijk (2015).

Todas estas mudanças conjunturais e suas implicações são oportunidades para inovar. O design evolui em um ambiente de transformações, mas exige reorientação, incluindo-as em seu processo de criação (Hands, 2009). Novos contextos provocam a mudança de foco na prática do design, consequentemente demandam um novo perfil de gestão (Press, 2011). Desta forma, conhecimento teórico e prático, compreensão de experiências do passado e informações sobre a tecnologia disponível no presente, em conjunto, vão permitir ao gestor de design enfrentar os desafios do futuro (Cooper e Junginger, 2011). Assim, identifica-se que a gestão de design se depara com três perspectivas para a definição do valor do design e do seu campo de atuação no âmbito das empresas e, ainda, aponta uma destas como área de interesse no que se refere à sociedade de modo mais abrangente (Cooper e Junginger, 2011). 
No contexto da oferta das empresas, a primeira perspectiva para a gestão de design está associada à gestão do design no nível operacional. Ela se dedica a projetar produtos, serviços, ambientes e marcas que geram vantagem competitiva. Envolve conceitos e ideias da prática de design, como ele é feito e sobre o que deve se interessar; agrega valor através da estética e da diferenciação (Cooper e Junginger, 2011). Esta abordagem indica duas áreas de interesse emergente: a maior integração entre as pessoas envolvidas nos processos criativos (Press, 2011) e a interação entre produtos, serviços, pessoas e lugares como protagonista deste sistema (Celaschi, 2010). Ambas as áreas levam a gestão de design a mudar de foco da economia industrial para a economia criativa e do conhecimento, de processos baseados na manufatura para processos baseados em informação e em ideias (Best, 2015).

Como um amadurecimento da consciência corporativa quanto ao design, a segunda perspectiva reside nas estruturas organizacionais. Ela envolve a administração de processos e a promoção da relevância do design no atingimento de propósitos estratégicos das empresas (Cooper e Junginger, 2011). No nível corporativo de gestão, o design é um agente de transformação que enfrenta dois paradigmas emergentes. Um é a mudança das relações entre a firma e o consumidor, que não mais são mediadas somente pelos produtos e serviços, mas também por meio de articulações nos processos de desenvolvimento destas ofertas (Steigleder e Tonetto, 2013). O outro envolve não só processos, enquanto jornadas compartilhadas, mas estratégias, enquanto planejamento para o futuro (Hands, 2009). Por tudo isso, a gestão de design se torna responsável por renovar o que as empresas oferecem (Bruce e Bessant, 2005).

Com um foco ampliado, a terceira perspectiva se relaciona a uma área de atuação mais recente para a gestão de design e diz respeito à transformação de valores. Qualidade de vida, saúde, liberdade, autoexpressão, autorrealização, tolerância, diversidade, solidariedade e pertencimento são progressivamente reconhecidos como valores tão essenciais quanto necessidades físicas e materiais (Zurlo, 2010). Por um lado, esta abordagem - quando aplicada às organizações - exige que estas migrem de um modelo econômico baseado na produção de bens de consumo para outro, no qual são valorizados o conhecimento e as relações humanas, ambicionando conquistar sustentabilidade em um contexto de bem estar social e ambiental (Cooper e Junginger, 2011). Por outro lado, extrapolando o espaço corporativo e atuando em uma conjuntura mais ampla, esta mesma abordagem, isto é, a transformação de valores, está relacionada à inovação social ${ }^{2}$ (Best, 2010). Em ambos os lados - corporativo e social - o design influencia comportamentos, transforma problemas em oportunidades, incorpora redes colaborativas aos processos criativos, estabelece novas relações entre localismo e globalização (Celaschi, 2010; Press, 2011).

Mudanças de contexto demandam novas habilidades e competências, incluindo entendimento cultural, liderança e uma visão de mundo abrangente, com grande interdisciplinaridade (Cooper et al., 2011). Novos papéis, métodos e atividades associadas à criatividade, comunicação efetiva e proatividade são essenciais para o design fazer a definição de seus contornos. Ainda não se conhece os limites do que

\footnotetext{
2 A inovação social leva em consideração uma visão abrangente de desenvolvimento, cujos objetivos não são pautados apenas por resultados econômicos; pelo contrário, ela é orientada pela busca: da justiça, da equidade, da solidariedade, da inclusão de grupos marginalizados, da expressão de individualidades, entre outros fatores sociais críticos (Manzini, 2008).
} 
pode ser projetado pelo design, portanto, para buscar estabelecer um protagonismo na vida contemporânea faz mais sentido concebê-lo o mais amplamente possível (Margolin, 2014). Na gestão de design do século XXI, o mais crucial dos projetos de design possivelmente é o seu próprio futuro.

\section{DESIGN ESTRATÉGICO, CONTEXTO E O FUTURO DAS ORGANIZAÇÕES}

Transformações no contexto de atuação das firmas são inevitáveis e a gestão de design deve prevê-las (Mozota et al., 2011). Ela oferece recursos para as organizações enfrentarem os desafios do futuro, valorizando o potencial visionário do design para responder aos valores mutáveis da contemporaneidade (Cooper e Press, 1995). Logo, de forma geral, gerenciar o design no nível estratégico das corporações é administrar a sua contribuição para o processo de formulação da estratégia (Mozota et al., 2011). Sendo assim, cabe aqui uma breve revisão sobre o que é estratégia. No campo da administração a estratégia é a área das empresas que tem por função pensar sobre o futuro (Kimbell, 2011). Ela é a concepção de como competir de forma bem sucedida, conquistando vantagens competitivas e oferecendo o desempenho almejado pelas organizações (Barney, 2002). Portanto, no contexto da globalização e do acirramento da concorrência, o estudo sobre decisões estratégicas se tornou importante para a empresa que decide ser competitiva, qualquer que seja a indústria em que opere (Jussani e Krakauer, 2010). Estratégia pode ser posição, isto é, a definição de determinados produtos em mercados específicos, mas também pode ser perspectiva, ou seja, a maneira da organização realizar as suas operações. Enquanto posição, ela se volta para o exterior, onde a oferta encontra o cliente. Como perspectiva, olha para dentro dela mesma (Mintzberg, 2008).

Independentemente do ponto de vista empregado, os processos de gestão organizacional são dirigidos por estratégias enquanto declaração de intenção e planos para o futuro. Como um senso de orientação, elas criam vantagem competitiva sustentável, além de descreverem o curso da ação e os recursos necessários para alcançar a visão da organização (Best, 2010). São reconhecidos três propósitos fundamentais da estratégia: o primeiro é definir a direção da empresa, estabelecendo uma visão para o futuro; o segundo é concentrar esforços em torno das vantagens competitivas, assegurando que os recursos sejam empregados na conquista dos objetivos; o terceiro é fornecer consistência ao longo do tempo, garantindo flexibilidade para reagir a mudanças no contexto. Deste modo, estratégia em um escopo amplo é mais do que um meio para alcançar lucratividade no curto prazo, é uma forma de criar vantagens competitivas que possibilitem prosperidade de longo prazo, antevendo se os negócios persistirão por mais 10 ou 20 anos (Cooper e Press, 1995).

As oportunidades para o design no campo da estratégia corporativa se tornaram mais evidentes a partir de duas situações mudanças. A primeira foi a alteração no conceito, uma vez que a estratégia deixou de ser percebida como um produto final que apenas precisava ser executado (Cooper e Junginger, 2011). Ao contrário, ela é interpretada como um processo, como ações em progresso. A segunda foi a variação na natureza da competição, ao questionar a ideia de que a estrutura do mercado era um fato consumado para a formulação da estratégia. De maneira oposta, as indústrias estão em constante transformação, permitindo gerar vantagem competitiva, ao se basear, não somente em novas tecnologias, mas na combinação 
intrinsecamente nova de fatores de mercado existentes (Kim e Mauborgne, 2005). 0 sucesso da estratégia e do design estratégico depende da integração entre eles (Mozota et al., 2011). Ambos - design e estratégia - exigem condições similares para se desenvolverem. Os dois reforçam um ao outro (Cooper e Press, 1995). E, para as organizações se adaptarem a transformações conjunturais é preciso dirigir os olhares da administração e do design para o futuro.

Percebido como algo desconhecido, o futuro não é um espaço livre de referências. Ele já está impactado pelo presente e pelo passado (Kimbell, 2011). Por isso, apesar de não se poder afirmar o que irá acontecer, é possível especular, imaginar, propor. Ou somente esperar e recear. O movimento das forças globais no contexto contemporâneo apresenta problemas nunca antes vistos pelas organizações. Muitas firmas reagem às mudanças, sobrevivem e prosperam. Outras são lentas ao responder a estes movimentos e veem deteriorar a sua capacidade de competir. Não planejam o seu futuro, trabalham com um horizonte de curto prazo e não percebem o potencial para obter crescimento sustentável (Hands, 2009). As falhas no processo de leitura do contexto ocorrem ao ignorar: necessidades latentes e como estas podem ser atendidas de múltiplas formas; valores sociais inovadores; novas e inesperadas soluções; ofertas obsoletas e desconectadas dos usuários; tecnologias emergentes (Best, 2010; Hekkert e Van Dijk, 2015). As empresas que fracassam ao avaliar a complexidade mutante da conjuntura em que atuam, geralmente possuem modelos de negócios que foram historicamente bem sucedidos e a nova situação desafia a sua cultura organizacional e as suas plataformas tecnológicas (Fraser, 2010).

Ao optar pela primeira alternativa, isto é, enfrentar as mudanças, o design estratégico se diferencia de demais funções organizacionais através da criatividade e da capacidade de assumir riscos, cruzando os limites do possível e do comprovável; inventando situações desconhecidas; explorando, sugerindo e testando novos tipos de arranjos (Hands, 2009). E, como melhores condições de competitividade no futuro exigem novas ideias e estas não se baseiam no conhecimento atual (Kimbell, 2011), a gestão de design nas organizações se dedica a duas tarefas: a primeira é o mapeamento do terreno estratégico, com o objetivo de antecipar comportamentos, necessidades, tendências; a segunda é a gestão de transições, com o propósito de preparar as organizações para aceitar e experimentar novas possibilidades (Topalian, 2011). Ambas as tarefas podem ser traduzidas em três habilidades do design estratégico: "ver", "prever" e "tornar visível" (Zurlo, 2010). Em conjunto, elas estabelecem uma convergência entre o conceito de visão estratégica sob a perspectiva do design, isto é, visão é uma forma da organização sustentar a habilidade de se transformar (Mozota, 2011); e sob a perspectiva da administração, na qual a visão expressa o que a organização deseja ser no futuro (Barney, 2002).

Ao exercitar a primeira habilidade - "ver"- é provável que se perceba que o contexto em que a organização atua contém premissas obsoletas, válidas quando a solução original foi proposta, mas que se tornaram ultrapassadas porque o mundo mudou, ou porque a perspectiva usada para olhar para ele se transformou. Assim, torna-se evidente a necessidade de se criar algo novo e se estabelece a segunda habilidade - "prever". Fazer previsões envolve criatividade e esta é uma faculdade inata do design nos processos estratégicos (Zurlo, 2010), mas a inovação - incremental ou radical -implica em considerar os riscos e as incertezas intrínsecos ao processo (Bruce e Bessant, 2005). Por fim, o conhecimento adquirido ao "ver"e ao "prever" é 
compartilhado na terceira habilidade - "tornar visível" - para que todos possam criar coletivamente o valor da oferta da firma (Best, 2010). No Quadro 3 são apresentados objetivos, metodologias e oportunidades de cada uma das três habilidades do design estratégico no que se refere a ações futuras.

Quadro 3 - Habilidades do design estratégico na busca por melhores condições de competitividade no futuro.

\begin{tabular}{|c|c|c|c|}
\hline & \multicolumn{3}{|c|}{ HABILIDADES DO DESIGN ESTRATÉGICO } \\
\hline & "Ver" & "Prever" & "Tornar visível" \\
\hline Objetivos & $\begin{array}{l}\text { Compreender a dimensão } \\
\text { sistêmica da oferta da } \\
\text { empresa e interpretar o } \\
\text { contexto. }\end{array}$ & $\begin{array}{l}\text { Antecipar o futuro, dar } \\
\text { sentido ao processo de } \\
\text { mudança, ter ideias. }\end{array}$ & $\begin{array}{l}\text { Converter conceitos } \\
\text { abstratos em material } \\
\text { tangível, tornar previsões } \\
\text { mais compreensíveis. }\end{array}$ \\
\hline Metodologias & $\begin{array}{l}\text { Qualitativas, que permitem } \\
\text { identificar valores culturais } \\
\text { dos usuários não expressos } \\
\text { ou racionalizados. }\end{array}$ & $\begin{array}{l}\text { Instrumentos de previsão } \\
\text { e métodos para a } \\
\text { construção de cenários. }\end{array}$ & $\begin{array}{l}\text { Materiais e narrativas } \\
\text { visuais, esboços e } \\
\text { simulações, modelos e } \\
\text { protótipos. }\end{array}$ \\
\hline Oportunidades & $\begin{array}{l}\text { Verificar mudanças e } \\
\text { perceber tendências que } \\
\text { motivam o início do } \\
\text { processo criativo. }\end{array}$ & $\begin{array}{l}\text { Agir de forma adequada } \\
\text { antes da situação prevista } \\
\text { se realizar. }\end{array}$ & $\begin{array}{l}\text { Apoiar e acelerar a } \\
\text { tomada de decisões para } \\
\text { se alcançar uma visão } \\
\text { comum. }\end{array}$ \\
\hline
\end{tabular}

Fonte: Elaborado pelos autores a partir das pesquisas de Press e Cooper (2003), Best (2010), Zurlo (2010), Mozota et al. (2011), Freire (2014), Hekkert e Van Dijk (2015).

Organizações que se dedicam a previsões sobre o futuro têm mais tempo para se preparar. Ao se deslocarem do presente para o amanhã, elas podem repensar soluções tradicionais, renovar produtos maduros e conceber outros (Bessant, 2005); criar oportunidades para se reinventar e mudar de direção (Topalian, 2011). Construir um futuro para os negócios no século XXI exigirá organização, inovação, liderança e capacidade de imaginar novas possibilidades (McBride, 2009). E, como o design é o responsável por renovar as ofertas que a organização oferece ao mercado, possivelmente não há futuro para os negócios que não o envolva (Bruce e Bessant, 2005). As empresas possuem diversos problemas, mas é essencial determinar aquele a ser resolvido e, então, focar na tarefa de projetar a solução apropriada (Lockwood, 2010). Desta forma, as habilidades intrínsecas ao design - a capacidade de ver e de reproduzir o que ele vê - são essenciais para o design estratégico operar efetivamente (Cooper e Junginger, 2011).

\section{CONCLUSÃO}

A complexidade do mundo contemporâneo provoca o surgimento de diferentes contextos - emergentes e futuros - impondo novos desafios ao design em aspectos sociais, econômicos e tecnológicos. Considerando que o design contribui para as empresas desenvolverem vantagens competitivas no longo prazo, o objetivo deste artigo foi compreender como. Para tal, foi realizada revisão bibliográfica que permitiu, no avançar de suas seções, estabelecer relações entre design estratégico, interação com os contextos de atuação do design e habilidades para responder a mudanças e fazer previsões. Conforme mostra a Figura 1, a gestão do design nos três níveis operacional, funcional e estratégico - ocorre em termos ideais integrada e 
simultaneamente, projetando de acordo com contextos vividos no presente, sugeridos por tendências emergentes e orientados para o futuro. Tais contextos possuem uma configuração elaborada a partir de aspectos selecionados pelo design estratégico de acordo com seus propósitos e potenciais ao "ver", "prever" e "tornar visível". Enfrentar situações desconhecidas demandam novas formas de pensar estrategicamente, assim, estas três habilidades do design estratégico no que se refere a ações que permitam às empresas competir de forma sustentável no futuro se relacionam com diferentes camadas de relações contextuais. "Ver" permite o acesso a informações presentes e emergentes; "prever" envolve criar cenários futuros e "tornar visível" possibilita tangibilizar alternativas para projetos que atendam demandas latentes e futuras.

Figura 1 - Relações entre design estratégico, interação com os contextos de atuação do design e habilidades para responder a mudanças.

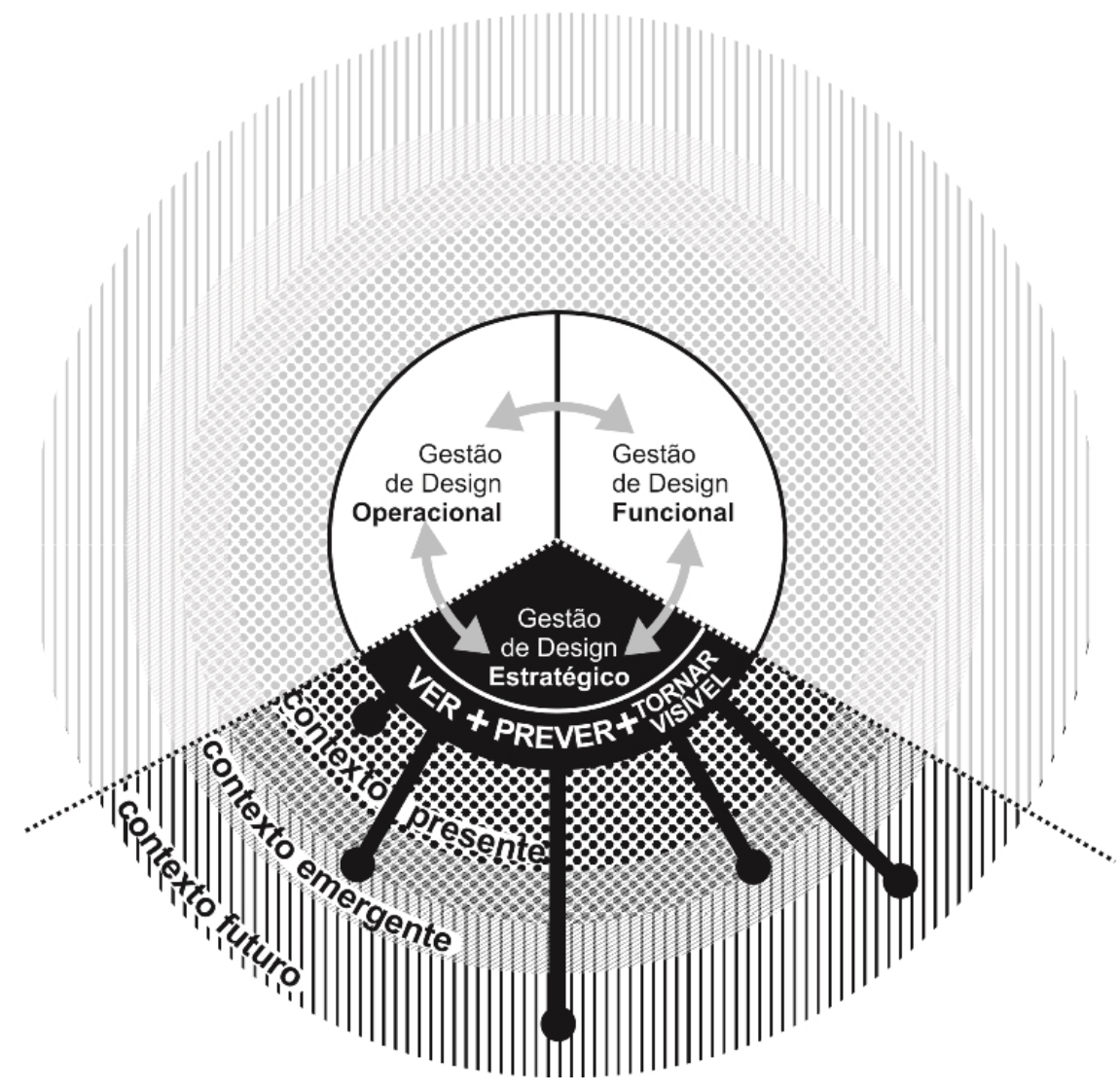

Fonte: figura elaborada pelos autores.

Para o design ser efetivo estrategicamente nestas circunstâncias mutáveis, ele precisa desenvolver novas ideias baseadas em conhecimentos que virão basicamente de três fontes. A primeira é a ampliação dos limites do design e a redefinição constante do que constitui um problema para ele, possibilitando desafiar o que é convencional. A segunda é a convergência entre design e outros campos do conhecimento, refinando as suas especificidades e explorando seu potencial criativo. A terceira é a propensão natural de agir como mediador entre as empresas, seu contexto e seus públicos de interesse, favorecendo o uso de métodos inclusivos, participativos e 
colaborativos, administrando conflitos e buscando soluções que satisfaçam todas as partes. Os designers são profissionais essenciais ao processo estratégico no qual a incerteza é um elemento intrínseco, pois contribuem com sua visão inventiva, plural e propensa ao risco, mas sem negligenciar a necessidade de apresentar alternativas justificáveis. Ao fazer previsões, o design pode não elaborar a resposta perfeita, mas é provável que a solução mais adequada para competir sustentavelmente no futuro seja desenvolvida a partir do aprendizado gerado por tentativas sinceras de inovação.

\section{REFERÊNCIAS}

BARNEY, J. Gaining and sustaining competitive advantage. New Jersey: Prentice Hall, 2002.

BESSANT, J. Why design? In: BRUCE, M., BESSANT, J. Design in business: strategic innovation through design. Essex: Prentice Hall, 2005.

BEST, K. The fundamental of design management. Lausanne: Ava, 2010.

BEST, K. Design management: managing strategy, process and implementation. Londres: Bloomsbury, 2015.

BRUCE, M. Marketing and design. BRUCE, M., BESANT, J. Design in business: strategic innovation through design. Essex: Prentice Hall, 2005.

BRUCE, M.; COOPER, R. Marketing and design management. London: Thomson, 1997.

BRUCE, M., BESSANT, J. Design in business: strategic innovation through design. Essex: Prentice Hall, 2005.

CELASCHI, F. Metaprojeto hoje: guia para uma fase de transição. In: DIJON DE MORAES - Metaprojeto: o design do design. São Paulo: Blucher, 2010.

COOPER, R. Design Management. In: HANDS, D. Vision and values in design management. Lausanne: Ava, 2009.

COOPER, R., et al. A. New design business models: implications for the future of design management. In: COOPER, R., et al. The handbook of d. management. New York: Berg, 2011.

COOPER, R., JUNGINGER, S. General Introduction: design management - a reflection. In: COOPER, R., et al. (Org.) The handbook of design management. New York: Berg, 2011.

COOPER, R.; PRESS, M. The design agenda: a guide to successful design management. New York: John Wiley, 2000 (1995).

DMI. What is Design Management? Disponível na internet por http em: https://dmi.site-ym.com/, Acesso em 20 de março de 2016.

DUMAS, A. MINTZBERG, H. Managing design, design management. Jornal of Design Management, 1990.

DUMAS, A. MINTZBERG, $H$. Managing the form, function and fit of design. Design Management Journal, 1991.

FRANCIS, D. Strategy and design. BRUCE, M., BESSANT, J. Design in business: strategic innovation through design. Essex: Prentice Hall, 2005.

FRASER, H. M. The practice of breakthrough strategies by design. Shamieh, M. Creating desired futures: how design Thinking innovates business. Base: Birkhauser, 2010. 
FREIRE, K. M. Design estratégico: origens e desdobramentos. XXI congresso Brasileiro de Pesquisa e Desenvolvimento em Design, 2014.

HANDS, D. Vision and values in design management. Lausanne: Ava, 2009.

HEKKERT, P., VAN DIJK, M. Vision in design: guidebook for innovators. Amsterdam: Bis, 2015. HOLSTON, D. The strategic designer. Cincinnati, How Books, 2011.

JUSSANI, A. C.; KRAKAUER, P. V. C.; PÓLO, E. F. Reflections on Blue Ocean strategy: a comparison with Ansoff's, Porter's, and Hax and Wilde's Strategies. Future Studies Research Journal: Trends and Strategies, v. 2, n. 2, art. 35, p. 17-35, 2010.

KIM, W. C., MAUBORGNE, R. A estratégia do oceano azul: como criar mercados e tornar a concorrência irrelevante. São Paulo: Campus, 2005.

KIMBELL, L. Manifesto for the M(B)A in designing better futures. In: COOPER, R., JUNGINGER, S., LOCKWOOD, T. (Org.) The handbook of design management. New York: Berg, 2011.

KOOTSTRA, G. L. The Incorporation of Design Management in Today's Business Practice. Rotterdam: DME - Design 235 Management Europe, 2009. Disponível em: http://www.designmanagementexcellence.com/wpcontent/uploads/2013/05/DME_Survey09.pdf. Acesso em: 25 de maio de 2016.

LOCKWOOD, T. Contextual perspectives. In: BEST, K. The fundamental of design management. Lausanne: Ava, 2010.

MAGALHÃES, C. Design estratégico: integração e ação do Design industrial. Estudos em Design, v. 3, n.1, p. 15-27, 1995

MAGALHÃES, C. F. Design estratégico: integração e ação do design industrial dentro das empresas. Rio de Janeiro, SENAI/DN, SENAI/CETIQT, CNPq, IBICT, PADCT, TIB, 1997.

MANZINI, E. Design para a inovação social e sustentabilidade: comunidades criativas, organizações colaborativas e novas redes projetuais. Tradução: Carla Cipolla. Rio de Janeiro: E-papers, 2008.

MARGOLIN, V. A política do artificial: ensaios e estudos sobre design. Rio de Janeiro: Civilização Brasileira, 2014.

MARTINS, R. F. F.; MERINO, E. A. D. A Gestão de design como estratégia

organizacional. Londrina: Eduel; Rio de Janeiro: Rio Books, 2011.

MCBRIDE, M. Views on design management. In: BEST, K. Design management: managing strategy, process and implementation. Londres: Bloomsbury, 2015.

MCCULLAGH, K. Contextual perspectives. In: BEST, K. The fundamental of design management. Lausanne: Ava, 2010.

MINTZBERG, H. Ascensão e queda do planejamento estratégico. Porto Alegre: Bookman, 2008.

MOZOTA, B. et al. Gestão do design. Porto Alegre: Bookman, 2011.

MOZOTA, B. B. Design strategic value revisited: a dynamic theory for design as organizational function. In: COOPER, R., et al.(Org.) The handbook of design management. New York: Berg, 2011. 
PRESS, M. Working the crowd: crowdsourcing as a strategy for codesign. In : COOPER, R., JUNGINGER, S., LOCKWOOD, T. (Org.) The handbook of d. management. New York: Berg, 2011 PRESS, M.; COOPER, R. The design experience: the role of design and designers in the twenty-first century. Urlington: Ashgate, 2003.

STEIGLEDER, A. P., TONETTO, L. M. A interface entre design estratégico e marketing estratégico. REVISTA DESTAQUES ACADÊMICOS, VOL. 5, N. 2, - CCHJ/UNIVATES, 2013.

TEIXEIRA, J. R. et al. Design estratégico: inovação, diferenciação, agregação de valor e competitividade. BNDES Setorial, Inovação, 35 - pg. 333-368, 2012.

TETHER, B. The role of design in business performance. Univ. of Manchester, 2005. TOPALIAN, A. Major challenges for design leaders over the next decade. In: COOPER, R., et al.(Org.) The handbook of design management. New York: Berg, 2011.

VILADAS, X. Managing design for profits. Barcelona: Indexbook, 2010.

VON STAMM, B. Innovation - what's design got to do with it? Design Management Review, Boston, v. 15, p. 10-19, 2004.

VON STAMM, B. The role of design in innovation: a status report. In: COOPER, R., et al.(Org.) The handbook of design management. New York: Berg, 2011.

ZURLO, F. Design strategico. Roma: Enciclopedia Treccani, 2010. Disponível na internet por http em: <http://www.treccani.it/enciclopedia/design-strategico (XXI Secolo)/>. Acesso em 20 de março de 2016. 